\title{
Emerging market of tobacco
}

\author{
Dipayan Datta $^{1 *}$, S. G. Ramesh Kumar ${ }^{2}$, M. B. Aswath Narayanan ${ }^{3}$, \\ A. Leena Selvamary ${ }^{2}$, A. Sujatha ${ }^{2}$
}

\begin{abstract}
${ }^{1}$ Postgraduate, ${ }^{2}$ Assistant Professor, ${ }^{3}$ Professor and Head, Department of Public Health Dentistry, Tamil Nadu Government Dental College and Hospital, Chennai, Tamil Nadu, India
\end{abstract}

Received: 25 March 2018

Accepted: 03 May 2018

\section{*Correspondence:}

Dr. Dipayan Datta,

E-mail: datta.dipayan2@gmail.com

Copyright: (C) the author(s), publisher and licensee Medip Academy. This is an open-access article distributed under the terms of the Creative Commons Attribution Non-Commercial License, which permits unrestricted non-commercial use, distribution, and reproduction in any medium, provided the original work is properly cited.

\begin{abstract}
Tobacco industry throughout the world started growing larger and larger. Large firms like British American Tobacco, Imperial Tobacco, China National Tobacco Co. etc. have been manufacturing and exporting tremendous amount of tobacco products. But concurrent research works were also growing to investigate the ill impact of tobacco on health and environment. Since the mid-1960s, strong evidence of the lethal effects of tobacco consumption has led to a sharp decline in official support for producers and manufacturers of tobacco. As the industry is struggling with reduction in smoking rates, huge sales taxes and strict regulations in mature markets, developing economies are offering the emerging markets with better prospects. Ideally, interventions that specifically address a market failure should be implemented as the "best" options. As part of moving towards a more sustainable form of globalization, a global enabling environment linked to local actions should focus on the following strategies: global information management; development of nationally and locally grounded action; global regulation, legal instruments, and foreign policy; and establishment of strong partnerships with purpose.
\end{abstract}

Keywords: Tobacco, Emerging markets, Low-income countries, Globalization

\section{INTRODUCTION}

The Europeans did not get their first taste of tobacco when Christopher Columbus brought a few tobacco leaves with him while returning to Europe after his voyage to the new world of America in 1492. Tobacco was introduced to France by the mid- $16^{\text {th }}$ century and French diplomats like Jean Nicot (for whom Nicotin is named) began to popularize the use of tobacco. ${ }^{1}$ Within 150 years of Columbus's finding "strange leaves", tobacco was being used around the globe. Its rapid spread and widespread acceptance characterise the addiction to the plant Nicotina tobacum. By the $17^{\text {th }}$ century, tobacco was introduced to India by the Portuguese traders. ${ }^{2}$

The $18^{\text {th }}$ century was the age of snuff and the $19^{\text {th }}$ century was the age of the cigar. The rise of the manufactured cigarette was the scenario in the $20^{\text {th }}$ century, and with it there was a great increase in the number of smokers. ${ }^{2}$ Tobacco industry throughout the world started growing larger and larger. Large firms like British American Tobacco, Imperial Tobacco, China National Tobacco Co. etc. started manufacturing and exporting tremendous amount of tobacco products. But concurrent research works were also growing to investigate the ill impact of tobacco on health and environment. Since the mid-1960s, strong evidence of the lethal effects of tobacco consumption has led to a sharp decline in official support for producers and manufacturers of tobacco. ${ }^{3}$ As the industry is struggling with reduction in smoking rates, huge sales taxes and strict regulations in mature markets, developing economies are offering the emerging markets with better prospects. As a result, the tobacco production in the developing countries has increased dramatically. In India, 
ITC (Imperial Tobacco Company of India Ltd.) was established in 1910. In 2014, nearly $0.24 \%$ of the agricultural land of India has been devoted to tobacco cultivation resulting in 720725 metric tons of tobacco production which in turn produced 82.12 billion cigarette production in $2016 .^{4}$

\section{GLOBALIZATION OF TOBACCO INDUSTRY}

The global shift towards trade liberalisation, facilitated by multilateral trade agreements such as the single package of World Trade Organization (WTO) trade agreements, regional, and bilateral agreements have encouraged the penetration of new markets by tobacco multinationals. The huge companies are attempting to manipulate globalization trends in their favour. In an increasingly globalised marketplace mega mergers and acquisitions have dramatically changed the face of the worldwide tobacco industry. Market liberalisation and penetration has been linked to a greater risk of increased tobacco consumption, especially in low and middle income countries. 5

The tobacco industry's strategies are intimately linked with the idea of international brands. The industry looks towards the creation of new "global brands" and a "global smoker" as one way of overcoming markets which have resisted the tobacco industries' onslaught. In other words, industry strategists are encouraging the homogenisation of the global tobacco industry and the creation of a new global shared culture enshrined in the concept of a global smoker. The global consolidation of the tobacco industry has become an obvious vehicle for promoting the idea of global smokers and their global brands. ${ }^{6}$

\section{GROWING AWARENESS IS THE DRIVE}

Although there is strong evidence that the tobacco marketing has high impact on the increased tendency of using tobacco among the young people there is also evidence of increased awareness among western people about the harmful effects of tobacco., ${ }^{7}$ In 2016 alone, tobacco use caused over 7.1 million deaths worldwide (5.1 million in men, 2.0 million in women). Most of these deaths (6.3 million) were attributable to cigarette smoking, followed by second-hand smoke $(884,000$ deaths). The current economic cost of smoking globally amounts to nearly 2 trillion dollars each year, equivalent to almost $2 \%$ of the world's total economic output. The majority of the total economic cost of smoking is the lost productivity of those sickened or killed by tobacco. ${ }^{9}$

Apart from the health issues, studies have also been conducted on environmental issues and the WHO estimates that about 200,000 hectares of woodlands and forests are destroyed each year to make way for tobacco farming. Almost 5\% of global deforestation can be attributed to the tobacco production. The tobacco products are also linked to an incredible amount of manufacturing and chemical waste along with the nonbiodegradable cigarette butts. $^{10,11}$

In the developed countries, the increasing awareness about the tobacco related outcomes are making people motivated to quit the habit of using tobacco products. The reducing levels of smoking in the West is causing enormous reduction in annual income from the production of tobacco products which leads the companies to move aggressively into developing countries and Eastern Europe. ${ }^{12}$ The Imperial Tobacco has started closing plants in the UK and in France as part of a cost-reduction programme that will see the company save $£ 300 \mathrm{~m}$ per year by the end of 2018. Other tobacco companies have instigated similar policies: BAT has closed 67 factories since 2000 and Japan Tobacco International recently announced the closure of its factory in Northern Ireland. ${ }^{13}$

\section{SHIFTING TARGET TOWARDS THE DEVELOPING COUNTRIES WITH EMERGING MARKETS}

Though the prevalence of smoking is falling in highincome countries, it is increasing in many middle- and low-income countries as the general awareness of the risks of smoking is relatively low in these regions. And it is expected that the global burden of disease caused by tobacco use will shift increasingly from high-income countries to countries with lower incomes. ${ }^{14}$

With smoking rates declining or peaking in the mature markets of the west, the transnational cigarette companies have looked to expand their international operations, especially in Asia, Latin America and Africa. They have exploited the recent opening up of countries that were once closed for trade because of political reasons, such as Central and Eastern Europe, and the former Soviet Union. The American companies, with the help of their Government, have used economic muscle - and the threat of sanctions - to open up countries in Asia, such as Taiwan and Japan. ${ }^{12}$

The companies have been trying to gain entry into China as for the tobacco companies, China, with some 300 million smokers, remains the prize. There is evidence of companies being involved in smuggling cigarettes into China. The industry has been accused of employing double standards in advertising, especially in targeting youth, in the difference of tar or nicotine levels between developed and developing countries. ${ }^{12}$

Emerging markets have long provided a breath of fresh air for tobacco companies. British American Tobacco, the world's second largest tobacco company by market share, returned to Myanmar last year, a decade after public pressure forced it to leave in 2003. Other tobacco companies followed suit, seeking new customers in a country where 45 per cent of men smoke or chew tobacco but only a small fraction smoke filtered cigarettes, 
according to the World Health Organisation. But after a tough two years in which cigarette volumes for the world's largest tobacco companies have fallen more quickly than usual, there are doubts about whether growth in developing markets can continue to be a panacea for the tobacco industry. ${ }^{14}$

\section{CONCLUSION}

Ideally, interventions that specifically address a market failure should be implemented as the "best" options. In case of the tobacco market such "best" interventions would include educating young people about the risks of addiction and disease from smoking or restricting their access to tobacco. However, the evidence suggests that these measures are relatively ineffective. ${ }^{15}$

In contrast, taxation, Albeit a blunt instrument and thus a "second best" intervention, is clearly effective at protecting children from taking up smoking. More practically, any tobacco control policy whose sole effect was to deter children from starting smoking would have little impact on numbers of smoking related deaths for many decades, since most of the projected deaths for the first half of the next century are those of current smokers Therefore, achieving health gains in the medium term requires encouraging adult smokers to quit. Taxation can also correct for any health costs imposed by smokers on others. However, taxation and various other interventions do impose costs on smokers. ${ }^{16}$

The globalization of tobacco marketing, trade, research, and industry influence represents a major threat to public health worldwide. The industry has used a wide range of methods to buy influence and power, and penetrate markets across the world. In contrast, until recently tobacco control lacked global leadership and strategic direction and had been severely underfunded. As part of moving towards a more sustainable form of globalisation, a global enabling environment linked to local actions should focus on the following strategies: global information management; development of nationally and locally grounded action; global regulation, legal instruments, and foreign policy; and establishment of strong partnerships with purpose. ${ }^{17}$

\section{Funding: No funding sources \\ Conflict of interest: None declared \\ Ethical approval: Not required}

\section{REFERENCES}

1. A brief history of tobacco, Available at: edition.cnn.com/US/9705/tobacco/history/

2. The history of tobacco, World Health Organization, Available at: http://www.who.int/tobacco/en/atlas2 .pdf. Accessed on 3 February 2018.

3. Manufacturing Cigarettes, World Lung Foundation| American Cancer Society, 2012. Available at: http.//tobaccoatlas.org:80/industry/manufacturing/te $\mathrm{xt} /$. Accessed on 24 February 2018.

4. The Tobacco Atlas. Country: India, American Cancer Society, Inc. and Vital Strategies, 2018, Available at: http://www.tobaccoatlas.org/country/ india/. Accessed on 24 February 2018.

5. Doll R, Crofton J, eds. Tobacco and health. London: Royal Society of Medicine Press. 1996: 206-221.

6. Morris P. Global regulatory network: internal report/ presentation. Philip Morris document. 1993: 2025599879-9920.

7. DiFranza JR, Wellman RJ, Sargent JD, Weitzman M, Hipple BJ, Winickoff JP, Tobacco promotion and the initiation of tobacco use: assessing the evidence for causality. Pediatrics. 2006;117(6):1237-48.

8. Borland R, Balmford J. Understanding how mass media campaigns impact on smokers, Tobacco Control. 2003;12(2):45-52.

9. The Tobacco Atlas, Sixth Edition, Jeffrey Drope and Neil W. Schluger, Editors, American Cancer Society, Inc., Atlanta, Georgia 30303 USA, 2018, Available at: http://www.tobaccoatlas.org. Accessed on 20 February 2018.

10. Environmental issues, Tobacco Free Initiative (TFI), World Health Organization, June, 1995, Available at: http://www.who.int/tobacco/research/economics /rationale/environment/en/. Accessed on 24 February 2018.

11. Dipayan D. Littered Cigarette Butts: A Grave Environmental Concern. J Dental Sci. 2018;3(2):164.

12. Tobacco Explained, The truth about the tobacco industry in its own words, World No Tobacco Day, World Health Organization. Available at: http://www.who.int/toh. Accessed on 24 February 2018.

13. Subber K. Tobacco companies feel the heat as emerging markets burn out, Financial Times, 2014, Available at: https://www.ft.com/content/c46596c268c4-11e4-9eeb-00144feabdc0. Accessed on 21 February 2018.

14. Savell E, Gilmore AB, Sims M, Mony PK, Koon T, Yusoff K, et al. The environmental profile of a community's health: a cross-sectional study on tobacco marketing in 16 countries, Bull World Health Organ. 2015;93:851-61.

15. Warner KE, Chaloupka FJ, Cook PJ, Manning WG, Newhouse JP, Novotny TE, et al. Criteria for determining an optimal cigarette tax: the economist's perspective. Tobacco Control. 1995;4:380-6.

16. Siegel M, Biener L, Rigotti NA. The effect of local tobacco sales laws on adolescent smoking initiation. Prev Med. 1999;29:334-42.

17. Yach D, Bettcher D. Globalization of tobacco industry influence and new global responses, Tobacco Control. 2000;9:206-16.

Cite this article as: Dipayan D, Ramesh Kumar SG, Aswath Narayanan MB, Leena Selvamary A, Sujatha A. Emerging market of tobacco. Int J Community Med Public Health 2018;5:2161-3. 